\title{
Journal of Oncology Research and Therapy
}

\section{The Antitumor Molecule TPEN Inhibits the Self-Renewal Potential of 5-Fluorouracil Resistant Colorectal Cancer Stem Cells}

\author{
Fata Akl $^{1 \neq}$, Zaynab Fatfat ${ }^{2 \neq}$, Soha Faraj ${ }^{1}$, Farah Ballout ${ }^{2}$, Maamoun Fatfat ${ }^{2}$, Hala Gali- Muhtasib ${ }^{2,3}$, Hala Khalife ${ }^{{ }^{*}}$ \\ ${ }^{1}$ Rammal Rammal Laboratory (ATAC Group), Faculty of Sciences, Lebanese University, Beirut, Lebanon \\ ${ }^{2}$ Department of Biology, American University of Beirut, Beirut, Lebanon \\ ${ }^{3}$ Department of Anatomy, Cell Biology and Physiological Sciences and Center for Drug Discovery, American University of Beirut, \\ Beirut, Lebanon \\ Fequal contribution
}

"Corresponding author: Hala Khalife, Rammal Rammal Laboratory (ATAC Group), Faculty of Sciences, Lebanese University, Lebanon.

Citation: Akl F, Fatfat Z, Faraj S, Ballout F, Fatfat M, et al. (2021) The Antitumor Molecule TPEN Inhibits the Self-Renewal Potential of 5-Fluorouracil Resistant Colorectal Cancer Stem Cells. J Oncol Res Ther 6: 10111. DOI: 10.29011/2574-710X.010111

Received Date: 24 August, 2021; Accepted Date: 08 September, 2021; Published Date: 14 September, 2021

\begin{abstract}
Background: The major causes of treatment failure and mortality in patients with colorectal cancer are the high recurrence rates and the drug resistance to the conventional chemotherapeutic agent 5-fluorouracil (5-FU). This resistance is greatly associated with a chemoresistant population of self-renewing cancer stem cells (CSCs). The antitumor molecule TPEN has been found to be effective against several cancers including colon cancer in vitro and in vivo. However, its effect on CSCs has not been evaluated yet. Here, we investigated the ability of TPEN to overcome chemoresistance and prevent cancer recurrence by targeting the selfrenewal potential of colorectal CSCs.
\end{abstract}

Methods: MTT assay was used to assess TPEN effect on the viability of 5-FU resistant colorectal cancer cells cultured in 2D monolayers. Sphere-formation and propagation assays were performed to assess the efficacy of TPEN on CSCs enriched from 5-FU sensitive and resistant colon cancer cell lines in 3D cultures over several generations.

Results: Our data showed that TPEN dose-dependently reduced the viability of 5-FU resistant colon cancer cells in 2D cell cultures. In 3D cultures, results showed that TPEN reduced the self-renewal capacity of CSCs derived from both cell lines over five generations. In addition, TPEN reduced the expression level of stem cell marker CD44 in colonospheres derived from both cell lines at generation 1.

Conclusion: Our results suggest that TPEN could be a potent therapeutic agent for eradicating and preventing the re-emergence of colorectal tumors.

Keywords: 5-Fluorouracil chemoresistance; Tumor relapse; Colorectal cancer stem cells; Colonospheres; Therapeutics; TPEN

\section{Introduction}

Colorectal cancer (CRC) is the third most frequent cancer and the second leading cause of cancer- related mortality in men and women worldwide. Around two million new cases and nearly one million deaths are estimated globally in 2020 [1]. Most of the CRC-related deaths are due to metastasis mainly to the liver and lungs [2]. Around $25 \%$ of CRC patients have metastasis at time of diagnosis, and $50 \%$ of patients diagnosed with CRC develop metastasis [3]. Chemotherapy with the conventional agent 5-fluorouracil (5-FU) is the mainstay therapeutic modality for metastatic CRC [4]. However, less than $25 \%$ of patients with advanced CRC respond to 5-FU. The therapeutic inefficacy of 5-FU is mainly due to drug resistance and tumor relapse [5]. Indeed, there is increasing evidence supporting the key role of the intratumoral heterogeneity, a defining feature of cancer, in drug resistance and tumor recurrence [6,7]. Cancer stem cells (CSCs) have been proposed to be the major contributor to intratumoral heterogeneity and chemotherapy resistance [8].

Colorectal cancer stem cells are a subpopulation of tumour cells that can self-renew, initiate a tumor, and produce liver and lung metastases when implanted in immunocompromised mice $[9,10]$. In addition, these colorectal CSCs were found to be resistant to the conventional chemotherapeutic agent 5-FU [11,12] and have been implicated in post-treatment tumor recurrence. Thus, targeting CSCs by a drug that simultaneously eliminates the 5-FU 


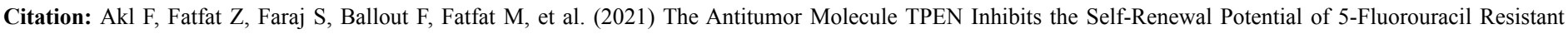
Colorectal Cancer Stem Cells. J Oncol Res Ther 6: 10111. DOI: 10.29011/2574-710X.010111

sensitive and resistant CSCs as well as the highly proliferating cells that they generate is of significance for clinical treatment and for effective and complete eradication of CRCs.

TPEN (N,N,N,N-Tetrakis (2-pyridylmethyl)-ethylenediamine), a lipid-soluble metal chelator, has been shown to be effective in depleting zinc and inducing apoptosis in several cancer cells both in vitro and in vivo [13-18]. In our laboratory, TPEN was found to selectively induce apoptosis in HCT116 human colorectal cancer cells without affecting their normal counterpart in vitro and in vivo [19]. We have also elucidated the mechanism of TPENinduced apoptosis [20]. Our findings revealed that TPEN caused DNA damage by chelating accumulated copper in colon cancer cells, engaging redox cycling reactions and inducing the generation of reactive oxygen species (ROS) [20].

In light of the promising potential of TPEN in selectively targeting 5-FU sensitive HCT116 cells, here we sought to investigate TPEN efficacy on targeting the self-renewal capacity of colorectal CSCs derived from the parental 5-FU sensitive and resistant HCT116 cell lines. This was done using the advanced three-dimensional (3D) culture sphere-formation and propagation assays over several generations. We found that TPEN has a promising inhibitory effect on colorectal CSCs population reflected by the reduced sphere forming ability over five generations and the diminished expression level of stem cell marker CD44 at generation 1 (G1) in colonospheres derived from both cell lines.

\section{Methods}

\section{Cell Culture and Treatment}

5-FU sensitive HCT116 human colorectal cancer cell line was purchased from ATCC and 5-FU resistant HCT116 human colorectal cancer cell line was provided from the laboratory of Prof. Nadine Darwiche (American University of Beirut, Lebanon). Both cell lines were cultured in RPMI 1640 (Sigma- Aldrich, Germany) with $20 \mathrm{mM}$ HEPES and L-Glutamine supplemented with $1 \%$ Penicillin- Streptomycin $(100 \mathrm{U} / \mathrm{ml})$ and $10 \%$ heatinactivated fetal bovine serum (FBS) (Sigma-Aldrich, Germany) in a humidified incubator $(95 \%$ air, $5 \% \mathrm{CO} 2)$ at $37^{\circ} \mathrm{C}$. TPEN (Sigma-Aldrich) was prepared in dimethylsulfoxide (DMSO). TPEN concentrations were prepared by serial dilutions in the cell culture media. The final DMSO concentration used on cells was $<0.3 \%$.

\section{MTT Cell Viability Assay}

The effect of TPEN on cancer cell viability was evaluated using the MTT ([3-(4,5- dimethylthiazol-2-yl)-2,5-diphenyltetrazolium bromide]) assay that is based on the ability of metabolically active cells to reduce the MTT dye to purple formazan. 5-FU resistant HCT116 colorectal cancer cells were seeded overnight in 96-well tissue culture plates at a density of 12,000 cells/well and then treated in sextuplicates with different concentrations of TPEN for 24,48 , and $72 \mathrm{~h}$. After treatment, $10 \mu \mathrm{L}$ of MTT reagent $\left(5 \mathrm{mg} / \mathrm{mL}\right.$ in PBS) was added to each well and incubated at $37^{\circ} \mathrm{C}$ for $2 \mathrm{~h}$. To solubilize the obtained formazan product, $100 \mu \mathrm{L}$ of isopropanol was added to each well and incubated at $37^{\circ} \mathrm{C}$ for $30 \mathrm{~min}$. The optical density (O.D.) of the reduced MTT was then recorded by an enzyme linked immuno-sorbent assay (ELISA) microplate reader at $595 \mathrm{~nm}$. Cell viability was presented as a percentage of the control calculated using the following formula.

$\%$ viability $=[$ mean O.D. treatment $/$ mean O.D. control $] \times 100$

\section{Sphere - Formation Assay}

The effect of TPEN on the self- renewal capacity of HCT116 colorectal CSCs was evaluated by testing their sphere forming efficiency when cultured in 3D over several generations. HCT116 colorectal cancer cells were suspended at a density of 2000 cells/ well in $50 \mu \mathrm{L}$ of a mixture of cold Matrigel ${ }^{\mathrm{TM}} /$ serum-free medium (1:1) and then seeded at the bottom rim of the well of a 24-well tissue culture plate. The Matrigel was allowed to solidify by incubation at $37^{\circ} \mathrm{C}$ for $45 \mathrm{~min}$. Subsequently, $500 \mu \mathrm{L}$ media with $5 \%$ FBS with or without TPEN was added gently in the middle of the well. Colonospheres were replenished with media or treatment every other day. They were counted and imaged at day 9 and 13 of sphere culture for the 5-FU sensitive and resistant cell lines, respectively.

\section{Propagation Assay}

Colonospheres were propagated over five generations. At the end of each generation, the medium was discarded and the colonospheres were dissociated from the Matrigel by digesting the latter with $500 \mu \mathrm{L}$ of dispase solution (Invitrogen, Carlsbad, CA) for $1 \mathrm{~h}$ at $37^{\circ} \mathrm{C}$. Colonospheres were collected by centrifugation and then incubated in $500 \mu \mathrm{L}$ trypsin/EDTA at $37^{\circ} \mathrm{C}$ for $1-2 \mathrm{~min}$. The single cells obtained from the dissociated colonospheres were re-seeded as described above.

\section{Immunofluorescence and 3D Imaging of Colonospheres}

The effect of TPEN on the expression of stem cell marker CD44 was evaluated by immunofluorescence. After treatment, colonospheres of G1 were collected with cold RPMI media and centrifuged in order to remove all Matrigel debris. Subsequently, colonospheres were fixed by formalin for $20 \mathrm{~min}$, and then washed with PBS thrice. They were permeabilized with $0.5 \%$ Triton X-100 for $30 \mathrm{~min}$ and blocked with blocking buffer for $2 \mathrm{~h}$ at room temperature. The blocking buffer consists of $0.1 \%$ BSA, $0.2 \%$ Triton X-100, $0.05 \%$ Tween- 20 , and $10 \%$ normal goat serum in PBS. Colonospheres were then washed and incubated with primary mouse anti- CD44 (1:50 dilution) antibody with blocking solution overnight at $4{ }^{\circ} \mathrm{C}$. Colonospheres were then washed with PBS and incubated with secondary Alexa fluoro 488 goat anti- 


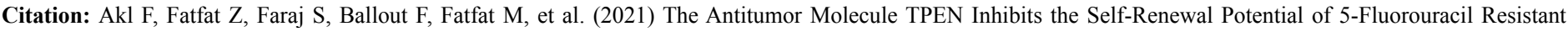
Colorectal Cancer Stem Cells. J Oncol Res Ther 6: 10111. DOI: 10.29011/2574-710X.010111

mouse antibody (dilution 1:200) for $1 \mathrm{~h}$ at room temperature. Subsequently, colonospheres were washed, counterstained with DAPI, and mounted with the anti-fade Fluorogel II. Colonospheres were then examined and imaged with Carl Zeiss LSM 710 laser scanning confocal microscope. Finally, the acquired images were analyzed using the Carl Zeiss ZEN 2012 image software.

\section{Statistical Analysis}

Data are presented as means \pm SD or means \pm SEM. Twotailed Student's t-test and one-way ANOVA with Tukey's posthoc tests were used to analyze the statistical significance of the difference between treatment groups and control groups. These tests were performed using Microsoft Excel 2013 software and IBM SPSS Statistics 25. Statistical significance was set at $* \mathrm{p}<$ $0.05, * * \mathrm{p}<0.01$ and $* * * \mathrm{p}<0.001$.

\section{Results}

\section{TPEN Reduces the Viability of 5-FU Resistant HCT116 Human Colorectal Cancer Cell Line}

We have previously evaluated TPEN's effect on the viability of 5-FU sensitive HCT116 colorectal cancer cells as well as on NCM460 non-tumorigenic colon cells and FHS74Int intestinal cells cultured in conventional 2D monolayers. We have found that $5 \mu \mathrm{M}$ of TPEN selectively killed 5-FU sensitive HCT116 colorectal cancer cells $24 \mathrm{~h}$ post-treatment without being toxic to nontumorigenic cells [19]. Therefore, we assessed the effect of TPEN on the viability of 5-FU resistant HCT116 colorectal cancer cells cultured in 2D. Cells were treated with TPEN at concentrations ranging between 1 and $10 \mu \mathrm{M}$ for 24,48 or $72 \mathrm{~h}$ after which cell viability was determined by MTT assay. The significant inhibitory effect of TPEN was achieved at 5 and $10 \mu \mathrm{M}$ for the 3 time points. The percentages of reduction in viability of 5-FU resistant cells induced by 5 and $10 \mu \mathrm{M}$ of TPEN were respectively 66 and $71 \%$ at $24 \mathrm{~h}, 73$ and $77 \%$ at $48 \mathrm{~h}, 86$ and $84 \%$ at $72 \mathrm{~h}$. The $\mathrm{IC}_{50}$ of TPEN at $48 \mathrm{~h}$ was $4.5 \mu \mathrm{M}$ (Figure 1).

\section{TPEN Targets an Enriched Population of 5-FU Sensitive and Resistant HCT116 Human Colorectal Cancer Stem-Like Cells}

Self-renewal capacity is one of the major hallmarks of stem cells that allows them to form and propagate spheres when cultured within Matrigel in 3D. We investigated TPEN efficacy on targeting self-renewal potential of colorectal CSCs derived from 5-FU sensitive and resistant cell lines by assessing their sphere forming ability over five generations. This was performed in $3 \mathrm{D}$ using sphere-formation and propagation assays. Colonospheres of G1 untreated or treated with TPEN were propagated by dissociating them into single cells and re-plating the resulting cells at the same density of 2000 cells/well. The re-seeded cells formed the colonospheres of the second generation (G2). This assay was repeated until the fifth generation (G5) in presence or absence of treatment.

Our data showed that the sphere forming unit of 5-FU sensitive and resistant HCT116 cells at each generation was lower in treated cells compared with that of the untreated control in a dose-dependent manner. Successive propagation and treatment of both cell lines over five generations with $1 \mu \mathrm{M}$ TPEN significantly reduced the sphere forming unit of 5-FU sensitive HCT116 cells by $66 \%$ (Figure $2 \mathrm{~A}$ ) and decreased that of 5-FU resistant HCT116 cells by remarkable $99 \%$ (Figure $2 \mathrm{~B}$ ).

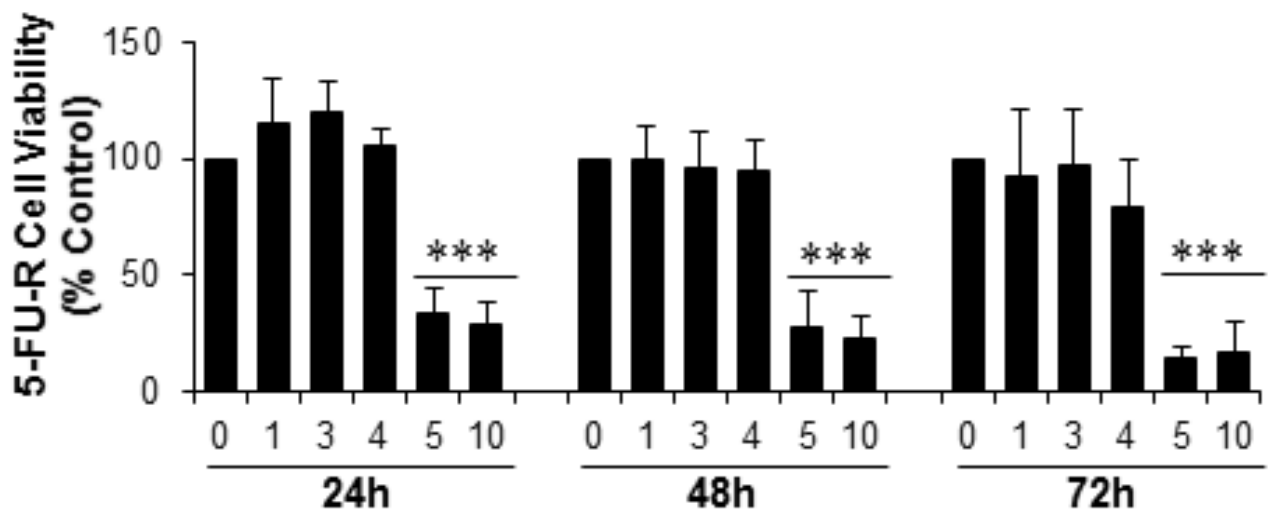

Figure 1: The effect of TPEN on the viability of 5-FU resistant (5-FU-R) HCT116 human colorectal cancer cells cultured in 2D. After treatment of cells with or without TPEN for 24,48 and $72 \mathrm{~h}$, cell viability was determined using MTT assay. The values are expressed as percentage of viable cells relative to untreated control. Each value represents the mean $\pm S D$ of $n=2$ experiments performed in sextuplicates. $* * * \mathrm{p}<0.001$ are significantly different from untreated control using two-tailed Student's t-test. 


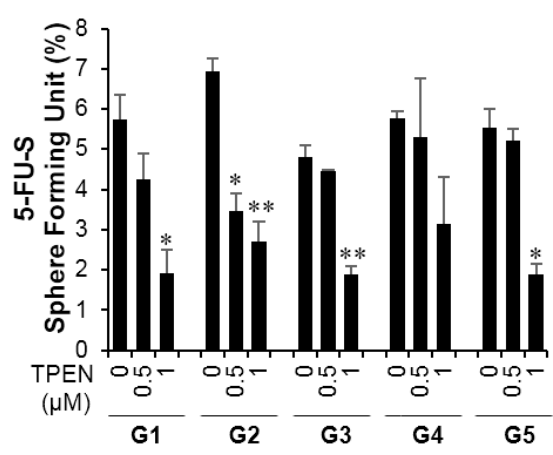

A

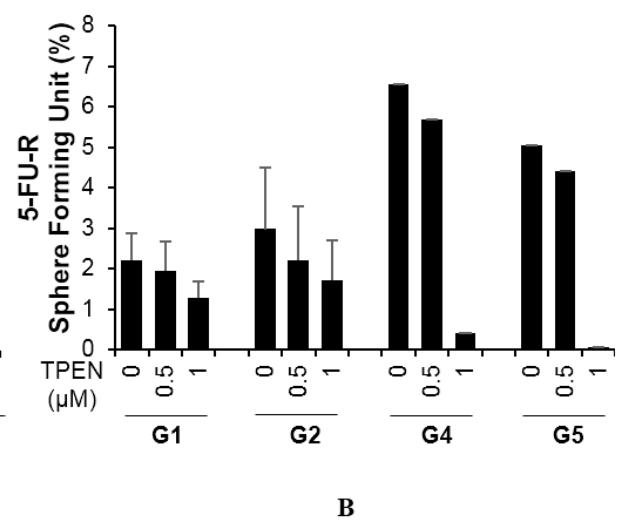

B

Figure 2: The effect of TPEN on the sphere forming ability of 5-FU sensitive (5-FU-S) and resistant (5-FU-R) HCT116 colorectal cancer stem cells. Sphere forming unit (SFU) over five generations for 5-FU-S (A) and four generations for 5-FU-R (B) HCT116 cells is shown in untreated or TPEN-treated $(0.5$ and $1 \mu \mathrm{M})$ cells. SFU values are calculated according to the following formula: SFU $=($ number of colonospheres counted / number of input cells) $\times 100$. Colonospheres were generated by propagating cells in Matrigel enriched culture plates in the presence or absence of TPEN. Data are represented as mean \pm SEM of $n=2$ for (A) 5-FU-S and as mean \pm SEM of $n=3$ for $\mathrm{G} 1, \mathrm{n}=2$ for $\mathrm{G} 2$ and as mean of $\mathrm{n}=1$ for $\mathrm{G} 4$ and $\mathrm{G} 5$ for (B) 5-FU-R HCT116 colonospheres. All experiments were performed in monoplicates. ${ }^{*} \mathrm{p}<0.05$ and ${ }^{* *} \mathrm{p}<0.01$ are significantly different from untreated control using one-way ANOVA with Tukey's post-hoc tests.

Interestingly, while $5 \mu \mathrm{M}$ of TPEN was needed to significantly reduce the viability of 5-FU sensitive and resistant HCT116 colorectal cancer cells grown in 2D, a dose of $1 \mu \mathrm{M}$ of TPEN was effective in decreasing the sphere forming unit of both cell lines.

We also investigated the effect of TPEN on the size of 5-FU sensitive and resistant HCT116 colonospheres. The diameter of the colonospheres was measured at each generation with or without treatment. Successive propagation and treatment of both cell lines over five generations with $1 \mu \mathrm{M}$ TPEN significantly decreased the diameter of 5-FU sensitive HCT116 colonospheres by $26 \%$ (Figure 3A) and diminished that of 5-FU resistant HCT116 colonospheres by 16\% (Figure 3B).

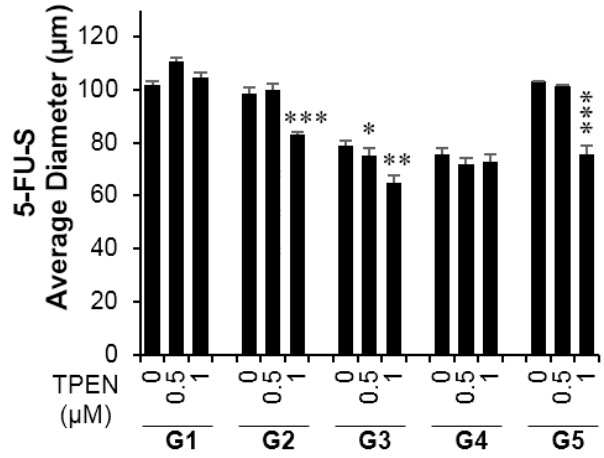

$\mathbf{A}$

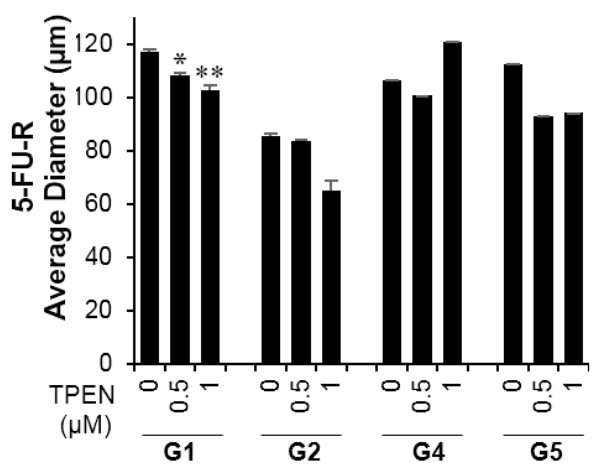

B

Figure 3: The effect of TPEN on the size of 5-FU sensitive (5-FU-S) and resistant (5-FU-R) HCT116 colonospheres. The diameter of colonospheres over five generations for 5-FU-S (A) and four generations for 5-FU-R (B) HCT116 colonospheres is shown in untreated or TPEN-treated $(0.5$ and $1 \mu \mathrm{M})$ cells. Colonospheres were generated by propagating cells in Matrigel enriched culture plates in the presence or absence of TPEN. Data are represented as mean \pm SEM of $n=2$ for (A) 5 -FU-S and as mean \pm SEM of $n=3$ for G1, $n=2$ for $\mathrm{G} 2$ and as mean of $\mathrm{n}=1$ for G4 and G5 for (B) 5-FU-R HCT116 colonospheres. All experiments were performed in monoplicates. *p $<$ $0.05,{ }^{* *} \mathrm{p}<0.01$ and ${ }^{* * *} \mathrm{p}<0.001$ are significantly different from untreated control using one-way ANOVA with Tukey's post-hoc tests. 


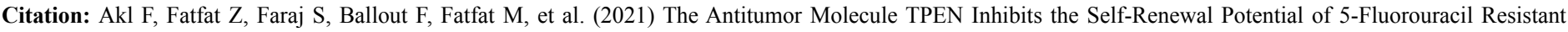
Colorectal Cancer Stem Cells. J Oncol Res Ther 6: 10111. DOI: 10.29011/2574-710X.010111

\section{TPEN Reduces the Expression of CD44 in 5-FU Sensitive and Resistant HCT116 Colonospheres}

To further investigate TPEN's effect on enriched HCT116 CSCs population, we evaluated the expression of the stem cell marker CD44. This marker was reported to play an essential role in maintaining the stemness of colon CSCs and in initiating colon cancer [21]. 5-FU sensitive and resistant HCT116 G1 colonospheres treated with $1 \mu \mathrm{M}$ TPEN were collected, immunostained for CD44 and counterstained with DAPI. Immunofluorescence staining showed that TPEN decreased the expression of CD44 in treated spheres derived from both cell lines compared to the untreated control (Figures 4A and 4B).

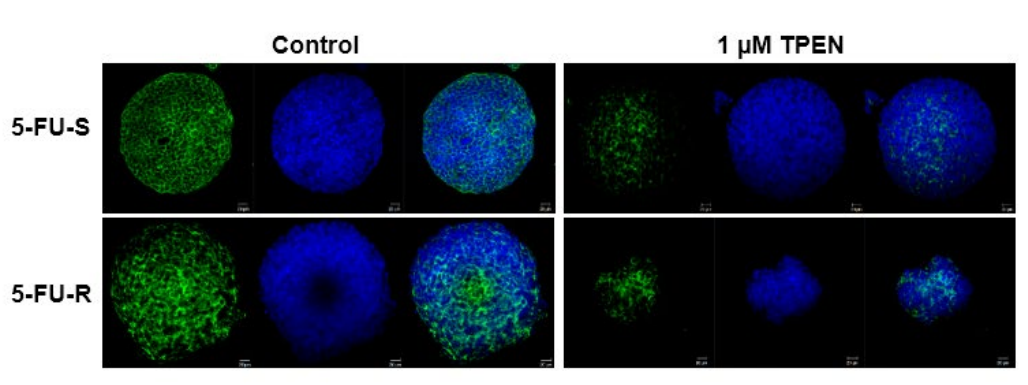

A

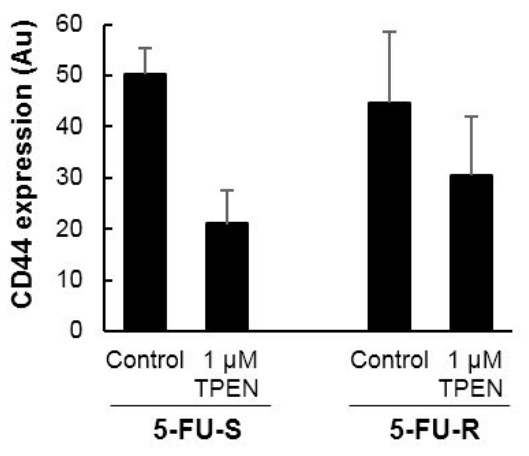

B

Figure 4: The effect of TPEN on the expression of CD44 in generation 1 colonospheres derived from 5-FU sensitive (5-FU-S) and resistant (5-FU-R) HCT116 cells. Colonospheres derived from 5-FU-S and 5-FU-R HCT116 cell line were untreated or treated with 1 $\mu \mathrm{M}$ of TPEN. The generated spheres were collected, fixed and immunostained for CD44. Representative images were obtained using confocal microscopy. Quantification of the intensity of CD44 staining in control and TPEN treated cells was performed using Carl Zeiss Zen 2012 software. The intensity of CD44 staining was normalized to the size of the spheres. Scale bar $20 \mu \mathrm{m}$.

\section{Discussion}

The standard therapy for metastatic CRC is the conventional agent 5-FU which acts by inhibiting the activity of thymidylate synthase enzyme leading to imbalances in the nucleotide pool. This results in the disruption of DNA replication, transcription, and repair which causes the death of cancer cells [22]. However, the therapeutic application of 5-FU has been restricted due to drug resistance and cancer recurrence leading to a 5-year survival rate of $13 \%$ in distant metastatic CRCs [5,23]. Numerous factors have been implicated in 5-FU resistance such as epigenetic alterations, disruption in cellular functions including apoptosis, autophagy, glucose metabolism and mitochondrial respiration in addition to cell cycle perturbation [24]. Recent studies have demonstrated that a population of cells with stem-like properties play an important role in 5-FU resistance $[11,12,25]$. Although 5-FU targets the rapidly proliferating cells in the tumor bulk, the quiescent or slowly cycling CSCs are resistant to 5-FU treatment [25]. The fact that 5-FU resistant HCT116 colonospheres are enriched with CSCs proved that 5-FU based chemotherapy failed to eradicate CSCs [26]. These dormant CSCs can enter the cell cycle and generate highly proliferating cancer cells resulting in tumor re-emergence. A recent report has shown that $\mathrm{CRC}$ cells enter stemness and quiescence in order to escape apoptosis induced by 5-FU [27].
Achieving a successful and complete course of CRC treatment requires selectively targeting the heterogeneous population of the colorectal tumor including the 5-FU sensitive and resistant cells as well as their derived CSCs while sparing the viable normal cells. Here, we have identified that the metal chelator TPEN has the potential to target the diverse population of the tumor and overcome 5-FU induced resistance in CRC without affecting normal cells. Although we and others have demonstrated TPEN's selective anti-cancer activity [17-20], no studies have assessed its effect on colorectal CSCs. In order to evaluate the inhibitory effect of TPEN to target the whole tumor including its stem cell population, we have used 5-FU sensitive as well as 5-FU resistant HCT116 colorectal cancer cell lines generated by exposure to increasing doses of 5-FU. HCT116 is an excellent model to use for assessing drug effects on CSCs and for studying the anti-tumor properties of TPEN. Colonospheres generated from HCT116 cell lines in 3D were found to be highly enriched with cells having stem-like properties and expressing the majority of known colorectal CSC markers [28,29]. Furthermore, TPEN was found to reduce the viability of 5-FU resistant HCT116 cell line at $\mathrm{IC}_{50}$ concentrations of less than $5 \mu \mathrm{M}$.

To assess TPEN effect on CSCs derived from both cell lines, we performed the sphere-formation and propagation assays. Our 


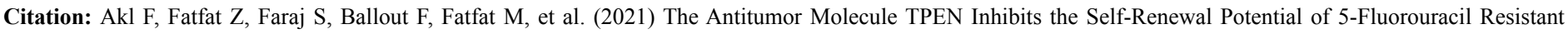
Colorectal Cancer Stem Cells. J Oncol Res Ther 6: 10111. DOI: 10.29011/2574-710X.010111

results showed that $1 \mu \mathrm{M}$ TPEN exerted a strong inhibitory effect on the stem cell population as revealed by a remarkable decrease in the sphere forming unit of both the sensitive and the resistant cell lines accompanied by a decrease in the size of colonospheres as well as in the expression of CSC marker CD44. Of note, CD44 was reported to be a CSC marker of high importance essential in maintaining stem-like properties in HCT116 cells [30]. CD44 knockdown decreased proliferation of these cancer cells and prevented tumor initiation in a mouse xenograft model [21]. In addition, CD44 expression was reported to be more pronounced in 5-FU resistant HCT116 colonospheres when compared to 5-FU sensitive reflecting its role in resistance to 5-FU [26].

TPEN has been shown to induce apoptosis in many cancer cell lines through various mechanisms dependent or not on its chelating activity. It was reported to induce the generation of ROS, the up- regulation of apoptotic mediators, the damage of DNA in addition to the inhibition of epithelial to mesenchymal transition (EMT) $[13,14,19,31]$. In colon cancer cells, TPEN was found to form a complex with copper and engage in redox cycling leading to the production of ROS. This results in double strands breaks (DSBs) in DNA and therefore activating DNA damage pathways ATM/ATR and DNA-PK $[19,20]$. Collectively, this data implies that TPEN acts by inducing cell death rather than by blocking cell proliferation.

Thus, it is reasonable to speculate that the decrease in selfrenewal capacity of colorectal CSCs enriched from 5-FU sensitive and resistant cell lines is likely to be in large part due to apoptosis induction. In addition, the reduction in HCT116 sphere forming unit and in colonospheres sizes induced by TPEN also suggest the involvement of apoptosis in eliminating colorectal CSCs. However, further mechanistic studies are needed to decipher the detailed molecular mechanisms for TPEN to eradicate colorectal CSCs.

In conclusion, our study demonstrated that TPEN is effective in depleting the CSC population enriched from 5-FU sensitive and resistant HCT116 colorectal cancer cell lines. Additional studies need to be conducted to provide insights into its mechanism of action and to further evaluate its effect on CSCs in animal models of $\mathrm{CRC}$ in order to advance it into clinical translation.

\section{Acknowledgments}

The authors thank the Lebanese National Council for Scientific Research and the Lebanese University for the funding. They also thank the staff of the core facilities in the DTS Building at the American University of Beirut for their help and support.

\section{Disclosure Statement}

The authors declare no conflicts of interest.

\section{Funding}

This work was supported by the Lebanese National Council for Scientific Research and the Lebanese University [Grant Number 1577/4]; and the University Research Board of the American University of Beirut [Grant Number 103951].

\section{References}

1. WHO, (2020) International Agency for Research on Cancer: GLOBOCAN: Cancer today.

2. Riihimäki M, Hemminki A, Sundquist J, Hemminki K. (2016) Patterns of metastasis in colon and rectal cancer. Sci Rep. 6: 29765.

3. Van Cutsem E, Oliveira J. (2009) ESMO Guidelines Working Group. Advanced colorectal cancer: ESMO clinical recommendations for diagnosis, treatment and follow-up. Ann Oncol. 20: 61-63.

4. Hammond WA, Swaika A, Mody K. (2016) Pharmacologic resistance in colorectal cancer: a review. Ther Adv Med Oncol. 8: 57-84.

5. Shin YK, Yoo BC, Hong YS, Chang HJ, Jung KH, Jeong SY, et al. (2009) Upregulation of glycolytic enzymes in proteins secreted from human colon cancer cells with 5-fluorouracil resistance. Electrophoresis. 30: 2182-2192.

6. Dagogo-Jack I, Shaw AT. (2018) Tumour heterogeneity and resistance to cancer therapies. Nat Rev Clin Oncol. 15: 81-94.

7. Vidal SJ, Rodriguez-Bravo V, Galsky M, Cordon-Cardo C, DomingoDomenech J. (2014) Targeting cancer stem cells to suppress acquired chemotherapy resistance. Oncogene. 33: 4451-4463.

8. Prieto-Vila M, Takahashi RU, Usuba W, Kohama I, Ochiya T. (2017) Drug Resistance Driven by Cancer Stem Cells and Their Niche. Int J Mol Sci. 18: 2574

9. O'Brien CA, Pollett A, Gallinger S, Dick JE. (2007) A human colon cancer cell capable of initiating tumour growth in immunodeficient mice. Nature. 445: 106-110.

10. Gao W, Chen L, Ma Z, Du Z, Zhao Z, et al. (2013) Isolation and phenotypic characterization of colorectal cancer stem cells with organspecific metastatic potential. Gastroenterology. 145: 636-646.

11. Todaro M, Alea MP, Di Stefano AB, Cammareri P, Vermeulen L, et al (2007) Colon cancer stem cells dictate tumor growth and resist cell death by production of interleukin-4. Cell Stem Cell. 1: 389-402.

12. Dallas NA, Xia L, Fan F, Gray MJ, Gaur P, et al. (2009) Chemoresistant colorectal cancer cells, the cancer stem cell phenotype, and increased sensitivity to insulin-like growth factor-I receptor inhibition. Cancer Res. 69: 1951-1957.

13. Hashemi M, Ghavami S, Eshraghi M, Booy EP, Los M. (2007) Cytotoxic effects of intra and extracellular zinc chelation on human breast cancer cells. Eur J Pharmacol. 557: 9-19.

14. Stuart $\mathrm{CH}$, Singh R, Smith TL, D'Agostino R Jr, Caudell D, et al. (2016) Prostate-specific membrane antigen-targeted liposomes specifically deliver the $\mathrm{Zn}(2+)$ chelator TPEN inducing oxidative stress in prostate cancer cells. Nanomedicine (Lond). 11: 1207-1222.

15. Yu Z, Yu Z, Chen Z, Yang L, Ma M, et al. (2019) Zinc chelator TPEN induces pancreatic cancer cell death through causing oxidative stress and inhibiting cell autophagy. J Cell Physiol. 234: 20648-20661.

16. Zhu B, Wang J, Zhou F, Liu Y, Lai Y, et al. (2017) Zinc Depletion by TPEN Induces Apoptosis in Human Acute Promyelocytic NB4 Cells. Cell Physiol Biochem. 42: 1822-1836. 
Citation: Akl F, Fatfat Z, Faraj S, Ballout F, Fatfat M, et al. (2021) The Antitumor Molecule TPEN Inhibits the Self-Renewal Potential of 5-Fluorouracil Resistant Colorectal Cancer Stem Cells. J Oncol Res Ther 6: 10111. DOI: 10.29011/2574-710X.010111

17. Gurusamy KS, Farooqui N, Loizidou M, Dijk S, Taanman JW, et al. (2011) Influence of zinc and zinc chelator on HT-29 colorectal cell line. Biometals. 24: 143-151.

18. Rojas-Valencia L, Velez-Pardo C, Jimenez-Del-Rio M. (2017) Metal chelator TPEN selectively induces apoptosis in K562 cells through reactive oxygen species signaling mechanism: implications for chronic myeloid leukemia. Biometals. 30: 405-421.

19. Fatfat M, Merhi RA, Rahal O, Stoyanovsky DA, Zaki A, et al. (2014) Copper chelation selectively kills colon cancer cells through redox cycling and generation of reactive oxygen species. BMC Cancer. 14: 527.

20. Rahal ON, Fatfat M, Hankache C, Osman B, Khalife H, et al. (2016) Chk1 and DNA-PK mediate TPEN-induced DNA damage in a ROS dependent manner in human colon cancer cells. Cancer Biol Ther. 17: 1139-1148.

21. Du L, Wang H, He L, Zhang J, Ni B, Wang X, et al. (2008) CD44 is of functional importance for colorectal cancer stem cells. Clin Cancer Res. 14: 6751-6760.

22. Wilson PM, Danenberg PV, Johnston PG, Lenz HJ, Ladner RD. (2014) Standing the test of time: targeting thymidylate biosynthesis in cancer therapy. Nat Rev Clin Oncol. 11: 282-298.

23. Siegel R, Ma J, Zou Z, Jemal A. (2014) Cancer statistics, 2014. CA Cancer J Clin. 64: 9-29.

24. Zhang N, Yin Y, Xu SJ, Chen WS. (2008) 5-Fluorouracil: mechanisms of resistance and reversal strategies. Molecules. 13: 1551-1569.
25. Paschall AV, Yang D, Lu C, Redd PS, Choi JH, Heaton CM, et al. (2016) CD133+CD24lo defines a 5-Fluorouracil-resistant colon cancer stem cell-like phenotype. Oncotarget. 7: 78698-78712.

26. Ballout F, Monzer A, Fatfat M, Ouweini HE, Jaffa MA, Abdel-Samad $R$, et al. (2020) Thymoquinone induces apoptosis and DNA damage in 5-Fluorouracil-resistant colorectal cancer stem/progenitor cells. Oncotarget. 11: 2959-2972.

27. Touil $Y$, Igoudjil W, Corvaisier M, Dessein AF, Vandomme J, Monté $D$, et al. (2014) Colon cancer cells escape 5FU chemotherapy-induced cell death by entering stemness and quiescence associated with the c-Yes/YAP axis. Clin Cancer Res. 20: 837-846.

28. Yeung TM, Gandhi SC, Wilding JL, Muschel R, Bodmer WF. (2010) Cancer stem cells from colorectal cancer-derived cell lines. Proc Natl Acad Sci U S A. 107: 3722-3727.

29. Botchkina IL, Rowehl RA, Rivadeneira DE, Karpeh MS Jr, Crawford H Dufour A, et al. (2009) Phenotypic subpopulations of metastatic colon cancer stem cells: genomic analysis. Cancer Genomics Proteomics. 6: 19-29.

30. Ju SY, Chiou SH, Su Y. (2014) Maintenance of the stemness in CD44(+) HCT-15 and HCT-116 human colon cancer cells requires miR-203 suppression. Stem Cell Res. 12: 86-100.

31. Zhang R, Zhao G, Shi H, Zhao X, Wang B, Dong P, et al. (2020) Zinc regulates primary ovarian tumor growth and metastasis through the epithelial to mesenchymal transition. Free Radic Biol Med. 160: 775783. 